\title{
KEPATUHAN PERAWAT MENERAPKAN PEDOMAN PATIENT SAFETY BERDASARKAN FAKTOR INDIVIDU DAN ORGANISASI
}

\author{
Christina Anugrahini i,2*, Junaiti Sahar ${ }^{3}$, Mustikasari $^{3}$ \\ 1. Akademi Keperawatan Pemerintah Kabupaten Belu Atambua, Nusa Tenggara Timur, Indonesia \\ 2. Program Studi Magister Fakultas Ilmu Keperawatan Universitas Indonesia, Depok 16424, Indonesia \\ 3. Fakultas Ilmu Keperawatan Universitas Indonesia, Depok 16424, Indonesia \\ *Email: anugrahini_christina@yahoo.com
}

\begin{abstract}
Abstrak
Penelitian ini adalah untuk mengidentifikasi hubungan antara faktor individu dan organisasi dengan kepatuhan perawat dalam menerapkan pedoman patient safety di RS X. Desain penelitian korelasi deskriptif dengan cross sectional. Sampel 144 perawat. Analisis data Chi Square, uji Tindependen, dan regresi logistik. Hasil penelitian ditemukan adanya hubungan yang bermakna antara usia, tingkat pendidikan, masa kerja, kepemimpinan, struktur organisasi, dan desain kerja dengan kepatuhan perawat dalam menerapkan pedoman patient safety. Variabel yang dominan adalah desain kerja ( $\mathrm{p}=0,000, \alpha=0,05 ; \mathrm{OR}=35,897)$. Disarankan agar pihak manajer rumah sakit mempertahankan dan meningkatkan desain kerja yang baik guna mencapai kepatuhan perawat dalam menerapkan pedoman patient safety untuk mencapai keselamatan klien di rumah sakit.
\end{abstract}

Kata kunci: faktor individu, faktor organisasi, kepatuhan perawat menerapkan pedoman patient safety.

Abstract

This study is to determine the relationship between individual and organizational factors on adherence of nurses in implementing patient safety guidelines in $R S X$. Descriptive study with cross sectional correlation design. The sample of 144 nurses. Data analysis Chi Square test, independent T test, and logistic regression. Results found significant relationship between age, educational level, years of service, leadership, organizational structure, and job design to the compliance of nurses in implementing patient safety guidelines. Dominant variable is the design of work ( $p=0.000, \alpha=0,05 ;$ OR $=35.897)$. Suggestion that the hospital managers to maintain and enhance good evil design to achieve compliance with the nurse in implementing patient safety guidelines to achieve patient safety in hospitals.

Keywords: individual factors, organizational factor, compliance of nurses in implementing patient safety guidelines

\section{Pendahuluan}

Keselamatan klien adalah klien bebas daricedera yang tidak seharusnya terjadi atau bebas dari cedera yang potensial akan terjadi (KKP-RS, 2008). Sembilan solusi keselamatan klien merupakan panduan untuk meningkatkan keselamatan klien. Asuhan keperawatan pada klien akan tercapai jika perawat taat dan patuh dalam penerapan pedoman patient safety. Perilaku disiplin merupakan perilaku yang taat dan patuh dalam peraturan (Matindas, 1987 dalam Unarajan, 2003).

Maryam (2009) mengemukakan bahwa 74,1\% klien merasa puas dengan penerapan tindakan keselamatan yang dilakukan perawat pelaksana di RS X. Pada tahun 2000 Institute of Medicine diAmerika Serikat menerbitkan laporan 'TO ERR IS HUMAN', Building a Safer Health System, yang artinya untuk mencegah kesalahan yaitu membangun kesehatan yang lebih aman. Hal ini terkait hasil penelitian di rumah sakit menurut WHO (2004) dalam Rapat Pleno Persi dan KKP-RS (2008) yakni di ruang perawatan akut pada 1992 di Utah dan Colorado dari 14.565 jumlah klien yang masuk di rumah sakit terdapat 475 angka kejadian tidak diharapkan (KTD). Sedangkan di New York, kejadian tidak diharapkan (KTD) ditemukan 1133 dari 30.195 jumlah klien yang masuk di rumah sakit.

Di negara Australia, menurut Quality in Australian Health Care Study (QAHC) dari 14.179 jumlah klien yang masuk di rumah sakit didapatkan 2353 KTD. Pada tahun 1999 sampai dengan 2000 di UK (United Kingdom) dari 1.014 jumlah klien yang masuk di rumah sakit terdapat 119 KTD. 
Di Indonesia, menurut data kasus dugaan malpraktik yang sudah dilaporkan pada tahun 2004 sampai dengan 2005, menurut Nadapdap terdapat 46 kasus. Uraian data tersebut diberbagai Negara mendorong segera dilakukannya penelitian dan pengembangan sistem keselamatan klien (Depkes, 2008). Kebijakan ini diterapkan diberbagai rumah sakit termasuk RS X. RS X termasuk rumah sakit yang diubah statusnya dari Perjan menjadi Badan Layanan Umum (BLU) sesuai dengan ditetapkannya Peraturan Pemerintah (PP) No. 23 Tahun 2005. Penerapan patient safety semakin ditingkatkan khususnya pada rumah sakit yang telah menjadi BLU.

Hasil studi pendahuluan didapatkan jumlah tenaga perawat di RS X pada tahun 2010 berjumlah 478 perawat. Perawat yang berlatar belakang pendidikan sarjana (S1) sebanyak 11 orang, DIII sebanyak 127 orang dan SPK sebanyak 45 orang. Banyaknya perawat dan pendidikan yang bervariasi, merupakan hal yang beresiko untuk terjadinya kesalahan yang dapat merugikan klien bahkan dapat berakibat fatal.

Berdasarkan rekapitulasi hasil observasi pada tahun 2008 dan 2009 di RS X masih terdapat angka kejadian dekubitus, infeksi jarum infus, infeksi luka operasi (ILO) dan KTD. Dalam konteks indikator klinik mutu pelayanan keperawatan dan pedoman pelaporan insiden keselamatan klien (KKP-RS, 2008) menjelaskan bahwa jumlah kejadian dekubitis, infeksi jarum infus, infeksi luka operasi dan KTD, merupakan suatu hal yang tidak boleh ada, karena hal ini dapat memberikan dampak negatif bagi klien. Berdasarkan uraian tersebut, peneliti tertarik untuk meneliti tentang hubungan faktor individu dan organisasi dengan kepatuhan perawat dalam penerapan patient safety.

\section{Metode}

Penelitian ini menggunakan metode deskriptif korelasi (descriptive corelational) dengan menggunakan pendekatan cross sectional, dimana variabel independen dan variabel dependen dilakukan pengukuran sekaligus dalam waktu bersamaan. untuk melihat hubungan antara faktor individu dan organisasi dengan kepatuhan perawat dalam menerapkan pedoman patient safety di RS X.
Sampel dalam penelitian ini adalah seluruh perawat pelaksana di ruang rawat inap RS X tahun 2010, yang berjumlah 144 orang. Kriteria inklusinya adalah: perawat yang mengetahui sembilan langkah penerapan pedoman patient safety dan bersedia menjadi responden. Kriteria eksklusi dalam penelitian ini adalah perawat pelaksana yang sedang cuti kerja, cuti sakit, dan tugas belajar.

Pengumpulan data dilakukan dengan menggunakan kuesioner A yang berisi faktor individu, yaitu data karakteristik perawat pelaksana yang merupakan data primer yang meliputi: usia, pendidikan, status pernikahan, dan masa kerja. Kuesioner B, faktor organisasi dikembangkan peneliti berdasarkan teori Ivancevich, Konopaske and Matteson(2006); Gillies (1994); Swanburg (2000), Depkes (2008), KKP-RS (2008). Kuesioner C berisikan tentang kepatuhan perawat dalam penerapan patient safety di ruang rawat inap.

Instrumen yang dipakai dibedakan untuk masingmasing variabel. Kuesioner kepatuhan perawat dalam penerapan patient safety dikembangkan peneliti dari Maryam (2009). Uji validitas di lakukan di RS Y didapatkan bahwa faktor organisasi dan kepatuhan perawat dalam menerapkan patient safety, didapatkan $\mathrm{r}$ hasil (corrected item-total correlation) lebih dari $r$ tabel $(0,361)$, sehingga dapat disimpulkan bahwa pernyataan tersebut adalah valid.

\section{Hasil}

Data diolah dan dianalisis menggunakan analisis univariat, biavariat uji T independent, Chi Square, dan analisis multivariat regresi logistik ganda.

\section{Karakteristik Responden}

Tabel 3.1. Distribusi Rata-rata Responden Menurut Umur

\begin{tabular}{ccccc}
\hline Variabel & $\begin{array}{c}\text { Mean } \\
\text { Median }\end{array}$ & $\begin{array}{c}\text { Standar } \\
\text { Deviasi }\end{array}$ & $\begin{array}{c}\text { Minimal- } \\
\text { Maksimal }\end{array}$ & $\mathbf{9 5 \%}$ CI \\
\hline \multirow{2}{*}{ Usia } & 38,81 & \multirow{2}{*}{10,676} & 23 & \multirow{2}{*}{$37,05-40,56$} \\
& 36,00 & & 56 & \\
Masa & 15,87 & 10,606 & 1 & $14,12-17,62$ \\
Kerja & 13,00 & & 31 & \\
\hline
\end{tabular}


Hasil penelitian menunjukkan rata-rata usia perawat dalam penelitian adalah 38,8 tahun dengan rentang 23 - 56 tahun (CI:37,05-40,56), standar deviasi 10,676 tahun, usia termuda 23 tahun, dan tertua 56 tahun. Umur rerata perawat pelaksana di instalasi rawat inap RS X ini berada dalam rentang umur produktif. Ratarata masa kerja perawat adalah 15,87 tahun $(95 \%$ CI: 14,12 - 17,62), dengan standar deviasi 10,606 tahun, lama kerja tersingkat 1 tahun dan terlama 31 tahun (lihat tabel 3.1).

Hasil penelitian menunjukkan bahwa sebagian besar perawat dalam penelitian ini berpendidikan D3 Keperawatan yaitu 74,3\% dan menikah yaitu $85,4 \%$ (lihat tabel 3.2). Hasil analisis ditemukan 60,4\% perawat mempersepsikan kepemimpinan baik, struktur organisasi baik $54,2 \%$, dan desain kerja baik $57,6 \%$, sedangkan imbalan dipersepsikan kurang sebesar 50,7\% (lihat tabel 3.3). Hasil penelitian menunjukkan $73,6 \%$ perawat pelaksana patuh dalam menerapkan pedoman patient safety (lihat tabel3.4).

\section{Hubungan Kepatuhan Perawat dalam Menerapkan Pedoman Patient Safety}

Perawat yang patuh dalam menerapkan pedoman patient safety mempunyai rata-rata usia 40,38 tahun, sedangkan perawat yang kurang patuh menerapkan pedoman patient safety mempunyai rata-rata usia 34,42 tahun. Uji T independent menunjukkan bahwa ada hubungan yang bermakna antara usia dengan kepatuhan perawat dalam menerapkan pedoman patient safety.

Penelitian ini juga memperoleh hasil bahwa perawat yang patuh dalam menerapkan pedoman patient safety mempunyai rata - rata masa kerja 17,36 tahun, sedangkan perawat yang kurang patuh dalam menerapkan pedoman patient safety mempunyai ratarata masa kerja 11,71 tahun. Uji T Independent menunjukan bahwa ada hubungan yang bermakna antara masa kerja dengan kepatuhan perawat dalam menerapkan pedoman patient safety.

Proporsi perawat dengan pendidikan D3 Keperawatan $(89,7 \%)$ dan S1 Keperawatan (66,7\%) lebih patuh dibandingkan dengan perawat yang berpendidikan
SPK. Hasil uji chi square menunjukkan bahwa ada hubungan yang bermakna antara tingkat pendidikan dengan kepatuhan perawat dalam menerapkan pedoman patient safety $(\mathrm{p}=0,000, \alpha=0,05, \mathrm{OR}=$ 151,118).

Proporsi perawat yang menikah $(76,4 \%)$ lebih patuh dibandingkan dengan perawat yang belum menikah. Hasil uji chi square menunjukkan bahwa tidak terdapat hubungan yang bermakna antara status pernikahan dengan kepatuhan perawat dalam menerapkan pedoman patient safety $(\mathrm{p}=0,113, \alpha=$ $0,05, \mathrm{OR}=2,431)$.

Proporsi persepsi perawat yang baik terhadap kepemimpinan kepala ruang 90,8\% lebih patuh dibandingkan dengan persepsi perawat yang kurang baik terhadap kepemimpinan kepala ruang. Hasil uji Chi Square menunjukkan bahwa ada hubungan yang bermakna antara kepemimpinan kepala ruangan dengan kepatuhan perawat dalam menerapkan pedoman patient safety $(\mathrm{p}=0,000, \alpha=0,05, \mathrm{OR}=10,972)$.

Tabel 3.2 Distribusi Frekuensi Responden Menurut Tingkat Pendidikan dan Status Perkawinan

\begin{tabular}{llcc}
\hline \multicolumn{1}{c}{ Variabel } & \multicolumn{1}{c}{ Kategori } & Frekuensi & $\begin{array}{c}\text { Presentase } \\
(\%)\end{array}$ \\
\hline Tingkat & 0. SPK & 31 & 21,5 \\
Pendidikan & 1. D3 Keperawatan & 107 & 74,3 \\
& 2. S1 Keperawatan & 6 & 4,2 \\
Status & 0. Belum Menikah & 21 & 14,6 \\
Perkawinan & 1. Menikah & 123 & 85,4 \\
& & & \\
\hline
\end{tabular}

Proporsi persepsi perawat yang baik terhadap struktur organisasi 92,3\% lebih patuh dibandingkan dengan persepsi perawat yang kurang baik terhadap struktur organisasi. Hasil uji chi square menunjukkan bahwa ada hubungan yang bermakna antara struktur organisasi dengan kepatuhan perawat dalam menerapkan pedoman patient safety $(\mathrm{p}=0,000, \alpha=$ $0,05, \mathrm{OR}=11,294)$.

Proporsi persepsi perawat yang baik terhadap imbalan (77,5\%) lebih patuh dibandingkan dengan persepsi perawat yang kurang baik terhadap imbalan. 
Hasil uji Chi Square menunjukkan bahwa tidak ada hubungan yang bermakna antara imbalan dengan kepatuhan perawat dalam menerapkan pedoman patient safety $(\mathrm{p}=0,398, \alpha=0,05)$.

Proporsi persepsi perawat yang baik terhadap desain kerja $(96,4 \%)$ lebih patuh dibandingkan dengan persepsi perawat yang kurang baik terhadap desain kerja. Hasil uji Chi Square menunjukkan ada hubungan yang signifikan antara desain kerja dengan kepatuhan perawat dalam menerapkan pedoman patient safety $(\mathrm{p}=0,000, \alpha=0,05, \mathrm{OR}=35,897)$.

\section{Faktor Penentu Kepatuhan Perawat dalam Menerapkan Pedoman Patient Safety}

Hasil analisis multivariat dengan enam tahapan menunjukkan bahwa terdapat satu variable, yaitu desain kerja, yang merupakan variabel paling dominan berhubungan dengan kepatuhan perawat dalam menerapkan pedoman patient safety dibandingkan variabel usia, tingkat pendidikan, status perkawinan, masa kerja, kepemimpinan dan struktur organisasi $(\mathrm{p}=$ $0,000, \alpha=0,05, \mathrm{OR}=35,897$ ).

\section{Pembahasan}

\section{Usia dengan Kepatuhan Perawat dalam Menerapkan Pedoman Patient Safety}

Hasil penelitian ini sesuai dengan penelitian (Sopiah, 2008) yang mengatakan usia juga menentukan kemampuan seseorang untuk bekerja, termasuk bagaimana merespon stimulasi. Peneliti berpendapat bahwa sebagian besar perawat di ruang rawat inap RS X berada pada usia yang produktif artinya pada usia ini memungkinkan perawat dalam masa kedewasaan dan kematangan dan dapat mengaplikasikan semua kompetensi yang dimiliki untuk menerapkan pedoman patient safety secara optimal.

\section{Masa Kerja dengan Kepatuhan Perawat dalam Menerapkan Pedoman Patient Safety}

наsil penelitian ini didukung oleh Ellis, et al. (2006) yang mengatakan bahwa perawat harus mempunyai pengalaman kerja yang cukup sehingga dapat mengerti tentang kebutuhan klien yang spesifik.
Peneliti berpendapat bahwa rata-rata masa kerja perawat pelaksana 16 tahun termasuk dalam kategori senior, artinya perawat di RS X rata-rata memiliki masa kerja yang cukup lama. Hal ini sangat mendukung untuk mencapai kepatuhan perawat dalam menerapkan pedoman patient safety.

\section{Tingkat Pendidikan dengan Kepatuhan Perawat dalam Menerapkan Pedoman Patient Safety}

Hal ini diperkuat oleh Hughes (2008) yang mengatakan bahwa tingkat pendidikan merupakan salah satu karakteristik individu yang dapat meningkatkan pengetahuan perawat untuk dapat menerapakan pedoman patient safety, sehingga dapat menurunkan angka kejadian tidak diharapkan (KTD). Peneliti berpendapat bahwa tingkat pendidikan perawat di RS $X$ sebagian besar adalah D III Keperawatan. Dengan tingkat pendidikan yang cukup tinggi, ketrampilan dan pengetahuan perawat juga akan bertambah. Selanjutnya perawat dapat berfikir secara rasional dalam melaksanakan tindakan keperawatan tersebut, sehingga dapat memberikan dampak bagi keselamatan klien di RS X Jakarta. Hal ini menunjukkan latar belakang pendidikan mempengaruhi kepatuhan perawat dalam menerapkan pedoman patient safety.

Tabel 3.3 Distribusi Frekuensi Responden Menurut Kepemimpinan, Struktur Organisasi, Imbalan, dan Desain Kerja yang Dipersepsikan oleh Perawat Pelaksana

\begin{tabular}{llcc}
\hline \multicolumn{1}{c}{ Variabel } & Kategori & Frekuensi & $\begin{array}{c}\text { Presentase } \\
(\mathbf{\%})\end{array}$ \\
\hline \multirow{2}{*}{ Kepemimpinan } & Kurang & 57 & 39,6 \\
& Baik & 87 & 60,4 \\
Struktur & Kurang & 66 & 45,8 \\
Organisa si & Baik & 78 & 54,2 \\
Imbalan & Kurang & 73 & 50,7 \\
& Baik & 71 & 49,3 \\
Desain Kerja & Kurang & 61 & 42,4 \\
& Baik & 83 & 57,6 \\
\hline
\end{tabular}

\section{Status Perkawinan dengan Kepatuhan Perawat dalam Menerapkan Pedoman Patient safety}

Peneliti berpendapat bahwa kepatuhan perawat perawat yang sudah menikah ataupun belum menikah tidak jauh berbeda tingkat kepatuhannya dalam menerapkan pedoman patient safety di RS X. 
Perawat menerapkan pedoman patient safety kepada klien yang dirawat sesuai dengan standar operasional prosedur (SOP) yang sudah diterapkan dari rumah sakit dan dilakukan dengan budaya kerja yang ada di rumah sakit tersebut.

\section{Kepemimpinan dengan Kepatuhan Perawat dalam Menerapkan Pedoman Patient safety}

Penelitian ini didukung oleh Schulke, Joshi, dan Mastal (2007) yang menemukan bahwa ada hubungan antara Chief Nursing Officers (CNO) dengan kepala ruangan di bangsal keperawatan untuk meningkatkan kualitas pelayanan dalam penerapan pedoman patient safety. Peneliti berpendapat bahwa kepemimpinan di RS X mempunyai kontribusi yang sangat besar terhadap kepatuhan perawat dalam menerapkan pedoman patient safety.

\section{Struktur Organisasi dengan Kepatuhan Perawat dalam Menerapkan Pedoman Patient safety}

Hal ini didukung oleh Winslow, et al. (2005), dalam penelitiannya menemukan bahwa struktur organisasi merupakan faktor yang berhubungan erat dengan kepatuhan perawat dalam menerapkan patient safety. Hughes (2008) menjelaskan bahwa kualitas dan keselamatan perawatan yang terkait dengan berbagai faktor dalam sistem, organisasi, dan lingkungan kerja merupakan hal yang mempengaruhi kualitas dan keselamatan klien. Yahya (2008) mengatakan bahwa struktur organisasi unit atau tim keselamatan klien di rumah sakit sangat berpengaruh terhadap keselamatan klien. Peneliti berpendapat bahwa sistem organisasi di RS X telah terstruktur dengan baik, sehingga garis komando dan garis koordinasi antar tiap bidang dapat terlaksana dengan baik. Dengan adanya struktur organisasi yang baik tersebut dapat mendukung kepatuhan perawat dalam menerapkan patient safety.

\section{Imbalan dengan Kepatuhan Perawat dalam Menerapkan Pedoman Patient Safety}

Penelitian ini ditemukan bahwa tidak ada hubungan yang bermakna antara imbalan dengan kepatuhan perawat dalam menerapkan pedoman patient safety. Hasil wawancara dengan bagian Kepala Bidang
Keperawatan mengatakan bahwa perawat mendapatkan insentif yang diberikan berdasarkan jenjang pendidikan, lama kerja, banyaknya dinas sore atau malam, jasa keperawatan perbulan, THR untuk anak sekolah, uang ulang tahun $\mathrm{RS}$ per tahun, perumahan, dan poli karyawan ruang perawatan untuk anak dan bunda. Beberapa fasilitas tersebut diharapkan dapat memenuhi kebutuhan perawat.

Tabel 3.4 Distribusi Frekuensi Kepatuhan Perawat dalam Menerapkan Pedoman Patient safety yang Dipersepsikan oleh Perawat Pelaksana

\begin{tabular}{llcc}
\hline \multicolumn{1}{c}{ Variabel } & Kategori & Frekuensi & $\begin{array}{c}\text { Presentase } \\
\text { (\%) }\end{array}$ \\
\hline $\begin{array}{l}\text { Kepatuhan } \\
\text { perawat dalam } \\
\text { menerapkan } \\
\text { pedoman patient } \\
\text { safety }\end{array}$ & Kurang Patuh & 38 & 26,4 \\
\hline
\end{tabular}

\section{Desain Pekerjaan dengan Kepatuhan Perawat dalam Menerapkan Pedoman Patient safety}

Hal ini didukung oleh penelitian yang dikemukakan oleh Wakefield (2008) yang mengatakan bahwa desain kerja dapat mempengaruhi perawat dalam menerapkan pedoman patient safety. Loh dan Gelinas (2004) mengatakan bahwa ada hubungan antara desain kerja dengan penerapan patient safety di rumah sakit.

Menurut peneliti, sejumlah 96,4\% yang mempunyai persepsi baik dan patuh dalam menerapkan pedoman patient safety tersebut memiliki suatu pandangan yang baik dalam pekerjaan sehari-hari. Desain kerja tersebut dapat diaplikasikan dengan baik sehingga akan semakin meningkatkan kepatuhan perawat dalam menerapkan pedoman patient safety.

\section{Kesimpulan}

Ada hubungan antara usia, tingkat pendidikan, masa kerja, kepemimpinan, struktur organisasi, dan desain kerja dengan kepatuhan perawat dalam menerapkan pedoman patient safety. Sedangkan, tidak ada hubungan antara status perkawinan dan imbalan dengan kepatuhan perawat dalam menerapkan pedoman patient safety. 
Faktor yang paling dominan berhubungan dengan kepatuhan perawat dalam menerapkan pedoman patient safety di RS X yaitu desain kerja. Agar pihak manajer rumah sakit mempertahankan dan meningkatkan desain kerja yang baik guna mencapai kepatuhan perawat dalam menerapkan pedoman patient safety untuk mencapai keselamatan klien di rumah sakit (TG, RS, YA).

\section{Referensi}

Departemen Kesehatan RI. (2008). Panduan nasional keselamatan pasien rumah sakit (Patient Safety). Jakarta: Depkes RI.

Ellis, et al. (2006). Staffing for safety: A Synthesis of the evidence on nurse staffing and patient safety. Ottawa: Ontario.

Gillies, A. D. (1994). Manajemen keperawatan sebagai suatu pendekatan sistem (3th Ed.). Philadelphia: WB Saunders Company.

Hughes, G.H. (2008). Patient safety and quality: An evidence based handbook for nurse. Diperoleh dari http://www.proquest.com.

Ivancevich, M.H., Konopaske, \& Matteson, T.M. (2006). Perilaku dan manajemen organisasi. (Jilid 2). Jakarta: Erlangga.

KKP-RS (2008). Pedoman Insiden Keselamatan Pasien (IKP) (Patient safety Incident Report) (Edisi 2). Jakarta: KPP-RS.

Loh, D. Y., \& Gelinas, L.S. (2004). The effect of workforce issues on patient safety. Nursing Economic, 22 (5), 266-272.
Maryam, D. (2009). Hubungan antara penerapan tindakan keselamatan pasien oleh perawat pelaksana dengan kepuasan pasien di IRNA Bedah dan IRNA Medik RSU Dr. Soetomo Surabaya (Tesis master, tidak dipublikasikan). Program Pascasarjana FIK UI, Jakarta.

Schulke, K., Joshi, M., \& Mastal, M.F. (2007). Nursing leadership: Championing quality and patient safety in the boardroom. Nursing Economic, 25 (6), 323-31.

Sopiah. (2008). Perilaku organisasional. Yogyakarta: Penerbit Andi.

Swanburg, R. C. (2000). Introductory management and leadership for nurses (2nd Ed.). Boston: Jones and Barlett Publishers.

Unarajan, D. (2003). Manajemen disiplin. Jakarta: PT Grasindo.

Wakefield, K. M. (2008). The quality chasm series: Implications for nursing, In Patient safety and quality: An evidence-based handbook for nurses, 1-19. Diperoleh dari www.ahrq.gov/qual/ nurseshdbk/nurseshdbk. pdf.

Winslow, et al. (2006). Staffing for safety: A synthesis of the evidence on nurse staffing and patient safety. Canadian Health Services Research Foundation and Foundation Canadiene, Ottawa. Diperoleh dari www.ccpnr.ca/PDFs/Nurse_Staffing_and_ Patient_Safety_2006.pdf.

Yahya, A. A. (2008). Patient safety is a key component of risk managemengent. Dalam Workshop keselamatan klien dan manajemen resiko klinis $R S X$ Jakarta, 1 - 3 April 2008.

Rasa enggan adalah kekuatan yang sangat besar, baik untuk mencapai keberhasilan atau menyebabkan kegagalan. Maka engganlah terlibat dalam hal-hal yang tidak menghasilkan. Dan bersegeralah dengan hal-hal yang menghasilkan, walau sekecil apapun.

- Mario Teguh - 